\title{
The Localization of the Asterion According to the Anatomical Landmarks of Posterior Cranial Fossa in Newborns: Clinical Implications
}

\author{
Localización del Asterión de Acuerdo con los Puntos Anatómicos de la \\ Fosa Craneal Posterior en Recién Nacidos: Implicaciones Clínicas
}

\author{
Mehmet T. Demir*; Cem Kopuz*; Mennan Ece Aydın Pirzirenli*; Fahrettin Çelik* \& Ufuk Çorumlu*
}

DEMIR, M. T.; KOPUZ, C.; PIRZIRENLI', M. E. A.; ÇELIK, F. \& ÇORUMLU, U. The localization of the asterion according to the anatomical landmarks of posterior cranial fossa in newborns: Clinical implications. Int. J. Morphol., 33(2):685-694, 2015.

SUMMARY: The purpose of this study was to determine the localization of the asterion according to the anatomical landmarks of posterior cranial fossa and its relation with sinuses for posterolateral surgical approaches in newborns. On 70 head-halves, a needle about $2 \mathrm{~mm}$ with diameter was placed on the centre point of asterion (posterolateral fontanel) by inserting into the whole cranial bony tissue by forming an right angle with the bony surface. Various localizations of asterion and its measurements from the internal and external anatomical landmarks were investigated on term neonatal cadavers. The localization of asterion was found as on the sigmoidtransverse sinus junction (STJ) (5., 6., 7., 8. squares) in 40\% of cases on right side and in 34\%, on left side. Additionally, it was located below the STJ (9., 10., 11., 12. squares) in $60 \%$ of cases, on right side and in $63 \%$ of cases on left side. We determined that the most frequent localization of asterion as the 11. square both for the right and left sides $12(34 \%)$ cases for the right side and $11(31,4 \%)$ cases for the left side. The asterion was not located on 1., 2., 3., 4., 5. and 12. squares on right side and 1., 3., 4., 8. and 9. squares on left side. It has been found that the region of asterion has an average distance value of $19.9 \mathrm{~mm}$ to internal acoustic meatus (MI), $31.7 \mathrm{~mm}$ to posterior clinoid process (PC), 34.4 to dorsum sellae (DS), $19.2 \mathrm{~mm}$ to jugular foramen (FJ), $23.0 \mathrm{~mm}$ to hypoglossal canal (HC), internally. The distance of asterion as $28.8 \mathrm{~mm}$ to zygoma root (ZR) and $22.3 \mathrm{~mm}$ to Henle's spine (HS) and $15.8 \mathrm{~mm}$ to mastoid tip (MT) and $35.9 \mathrm{~mm}$ to external occipital protuberance (PE) were observed. By the guide of point asterion on newborns the area of $1 \mathrm{~cm} 2 \mathrm{on}$ this point which was placed on superior 4 squares of our scale diagram is suggested as a safe area of placement of first burr hole to avoid from the risk of bleeding of sigmoid and transverse sinuses on craniotomies of posterior fossa.

KEY WORDS: Asterion; Sigmoid sinus; Transverse sinus; Retrosigmoidal approach; Anatomy; Newborn; Posterior cranial fossa.

\section{INTRODUCTION}

The surgical anatomy and approaches of cranial basis of adults are well defined in literatures (Brockmeyer et al., 2003; Day et al., 1996; Lang \& Samii, 1991; Ribas et al., 2005; Teo et al., 1999). The lesions that effected the cranial basis on children is rare and generally are not treated with major surgery. As a result of this, the cranial basis is a rare interest of literatures of pediatric neurosurgery (Brockmeyer et al.). Recently the neurosurgeons have treated the pathologies with minimally invasive methods (Lang \& Samii). These have made it necessary to access the petroclival area by direct and indirect routes (Lang, 2001). On the operations of cerebellopontin edge, according to their experiences, neurosurgeons have defended the retrosigmoid approaches which was more respective (Day \& Tschabitscher, 1998; Lang \& Samii; Lang). With this approach surgeons gain a good sight to the cerebellopontine edge by using a close dural incision near these sinuses with the thought of acception of the transvers and sigmoid sinuses as a landmark (Day \& Tschabitscher; Janetta et al., 1986; Lang \& Samii; Lang; Sripairojkul \& Adultrakoon, 2000).

The most important component of the steps of operation is the settlement of the first burrhole at the standart approaches to the lateral posterior cranial base (Avci et al., 1993; Day \& Tschabitscher). The injuries of the venous sinus placed at this region may be the cause of the intraoperative 
complications which will be the source of postoperative neurological morbidity and mortality. At a stage of planning of surgical approaches to the posterior fossa, the isolation of surface landmarks have a great importance for the exact definition of placements of underlying deep structures beneath the cranial bone (Avci et al.; Day \& Tschabitscher; Keskil et al., 1993).

The asterion, one of the important surface landmark for approaches of the posterior cranial basis is defined as the junction point of parietomastoid and occipitomastoid sutures "Lambdoid", which coincides with the site of the posterolateral fontanella, in the neonatal skull which closes during the second year (Avci et al.; Bonilla et al., 2012; Brockmeyer et al.; Day \& Tschabitscher; Lang \& Samii; Mwachaka et al., 2010; Rhoton, 1996; da Silva et al., 2010; Sripairojkul \& Adultrakoon; Standring, 2008). It is accepted as the first landmark at combine petrosal approaches for the cranial basis, and as the respectable landmark for the duramater of posterior fossa lying under it (Day \& Tschabitscher; Mwachaka et al.; Sripairojkul \& Adultrakoon; Tubbs et al., 2009). But, its reliability has been put into question due to its population variability in position using external anatomical landmarks (Kemkes et al., 2006).

The localization of asterion is very important for the lateral approaches to the posterior fossa (Day \& Tschabitscher; Lang). Also surgical approaches to this region require the knowledges of venous variations around the confluence sinuum (Kopuz et al., 2010). Newborns especially have a different venous drainage patterns of posterior fossa (Kopuz et al.). The variation of the asterion location may lead to potential sinus laceration burrhole placement and mastoid drilling (da Silva et al.). In addition, the very different kinds of variations of this landmark depending on its formation and placement, especially in newborn period was the reason of the difficulties and problems of studies coming to this time (Day \& Tschabitscher). The development of modern microsurgery and additionally with the placement of important imaging techniques such as MRI, CT etc., the morphometric measurement values or the anomalies or the variations which were defined with these investigated measurement values were gained importance on different groups or populations.

In newborns and at the stages of childhood because of difficulties of intracranial surgery of this region or approaches of posterior cranial fossa. Additionally, because of less number of studies in literature on the localization of asterion in newborns, a defination study in this area was planned to help clinicians involved in posterior fossa surgery of newborns.

\section{MATERIAL AND METHOD}

This study was performed on 70 head-halve specimens of 35 randomly selected neonatal cadavers (19 female and 16 male) aged between 38-40 gestational weeks , fixed with $10 \%$ formalin. The specimens of neonatal cranial base were obtained from the collection of Medical Faculty of Ondokuz Mayıs University, Department of Anatomy.

The scalps of craniums was totally lifted by anatomic incisions, and the exact location of asterional area was defined on bony surface. The asterional area is defined as the posterolateral fontanelle -a rough circle between the three bony structures formed by a circle comprising the edges of temporal, parietal and occipital bones of exact defination. The asterion is defined as the center point of posterolateral fontanelle which has rough circular shape on the neonatal specimens. The calvarias was removed by macroscopic dissections for the defination of internal parameters. The approaches to the posterior cranial fossa were performed on aspect as externally. After the replacement of hair - hairy skin and superficial smooth tissue, the key surface structures (zygoma root, Henle's spine, mastoid tip) were evaluated on each specimens (Fig. 1). The duramater, brain and brain stem were removed by protecting the sinuses and their confluence (Figs. 2-4).

The dural venous sinuses were exposed with internal landmarks on posterior cranial base. A needle about $2 \mathrm{~mm}$ with diameter was placed on the center point of asterion by inserting into the whole cranial bony tissue by forming an right angle with the bony surface (Fig. 1). A transparent scale diagram was formed with $1.5 \times 2 \mathrm{~cm}$ sizes and the diagram was divided into 12 equal squares with the $0.25 \mathrm{~cm} 2$ areas. These squares were numbered from 1 to 12 for the determination of each small areas. The one third (1/3) upper part of this scale diagram, by an another definition; the mid point of lower border of 1., 2., 3., 4. squares was settled on superior mid point of sigmoid - transverse sinus junction (STJ). The localization of asterion on the scale diagram was determined (Fig. 5).

The following distances were bilaterally measured by electronic digital caliper on each specimen: On external aspects, Asterion (A)- Zygoma root (ZR), A- suprameatal crest "Henle spine" (HS), A-Mastoid tip (MT), A-External occipital protuberance (PE) (Fig. 1).

On internal aspects, posterior cranial fossa, AInternal acoustic meatus (MI) A-Posterior clinoid process (PC), A- Dorsum sellae (DO), A-Jugular foramen (FJ), APoint that abducens nerve perforates the duramater (C6), A- 


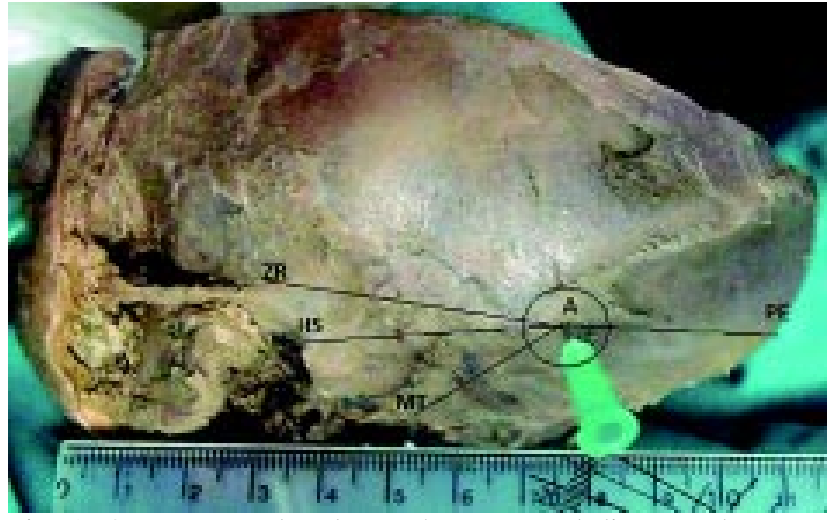

Fig. 1. On a neonatal cadaver, the measured distances between asterional region and determined external parameters were shown. The needle* extracranially inserted into asterion (middle point of posterolateral fontanelle). A= Asterion, HS= Henle's spine, MT= Mastoid tip, $\mathrm{PE}=$ External occipital protuberence, $\mathrm{ZR}=$ Zygoma root.

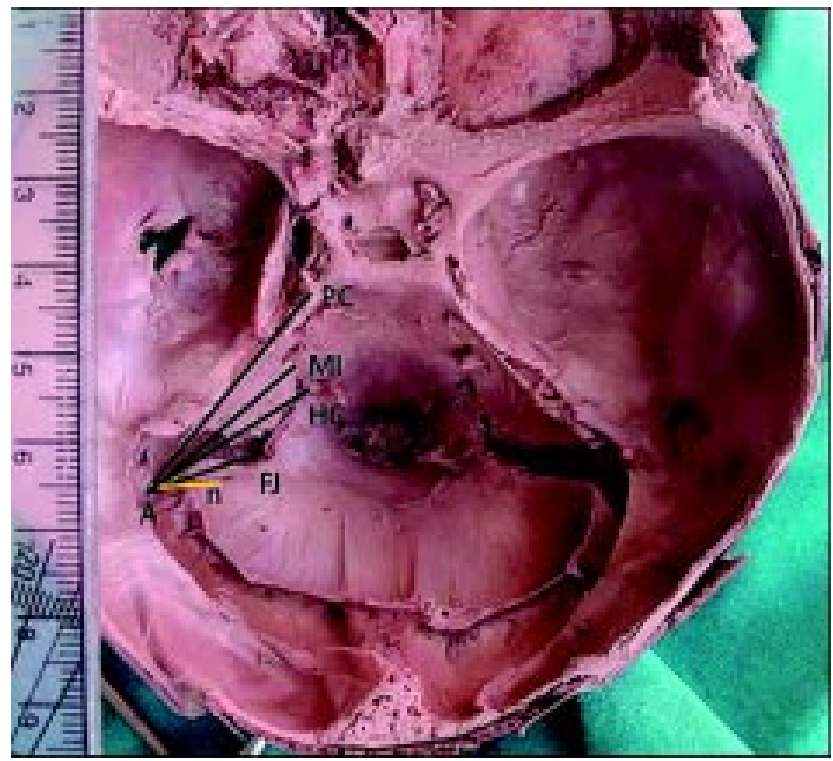

Fig. 2. In posterior cranial fossa (left head- halve) the measured distances between asterional region and determined internal parameters. After the needle was externally drilled through the bone perpendicular, its placement internally. $\mathrm{MI}=$ Internal acoustic meatus, $\mathrm{PC}=$ Posterior clinoid process, $\mathrm{FJ}=$ Jugular foramen, $\mathrm{HC}=$ Hypoglossal canal, $\mathrm{A}=$ Asterion, $\mathrm{n}=$ needle.

Hypoglossal canal (HC), A- Internal occipital protuberance (PI), A- Middle point of anterior margin of foramen magnum (FA), A- Middle point of posterior margin of foramen magnum (FP), A- Middle point of lateral margin of foramen magnum (FL), A- sigmoid-transverse sinus junction (STJ), A- Transvers sinus (TS) (middle point of distance between confluence sinuum and STJ), A- Sigmoid sinus (SS) (middle point of distance between jugular foramen and STJ), ASuperior petrosal sinus (SP) (middle point of distance

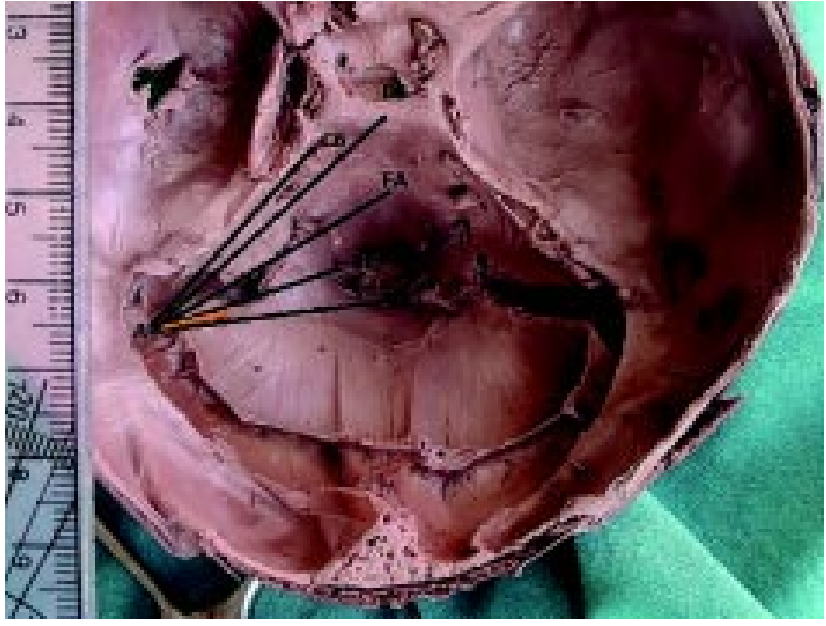

Fig. 3. In posterior cranial fossa (left head- halve) the measured distances between asterional region and determined internal parameters. After the needle was externally drilled through the bone perpendicular,its placement internally. A=Asterion, DS= Dorsum sellae, $\mathrm{C} 6=$ Point that abducens nerve perforates the duramater, $\mathrm{FA}=$ Middle point of the anterior margin of foramen magnum, $\mathrm{FP}=$ Middle point of the posterior margin of foramen magnum, $\mathrm{FL}=$ Middle point of the lateral margin of foramen magnum.

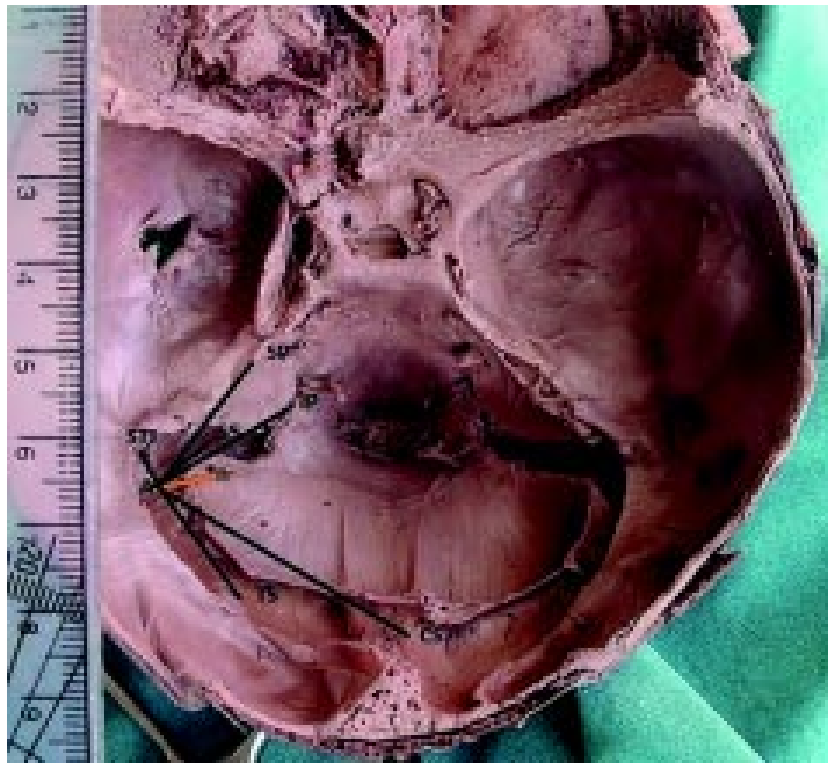

Fig. 4. The localization of the neddle inserted from the point asterion to the inner posterior cranial base (left head- halve) and the measured distances between this point and sigmoid-transverse sinus junction and other sinuses. STJ= Sigmoid-transverse sinus junction, $\mathrm{TS}=$ Transverse sinus, $\mathrm{SS}=\mathrm{Sigmoid}$ sinus, $\mathrm{CS}=$ Confluence of sinuses, $\mathrm{SP}=$ Superior petrosal sinus, $\mathrm{IP}=$ Inferior petrosal sinus, $\mathrm{n}=$ neddle.

between PC and place that the SP drained), A- Inferior petrosal sinus (IP) (middle point of distance between PC and FJ), A- Confluens sinuum (CS) (Figs. 2-4). 


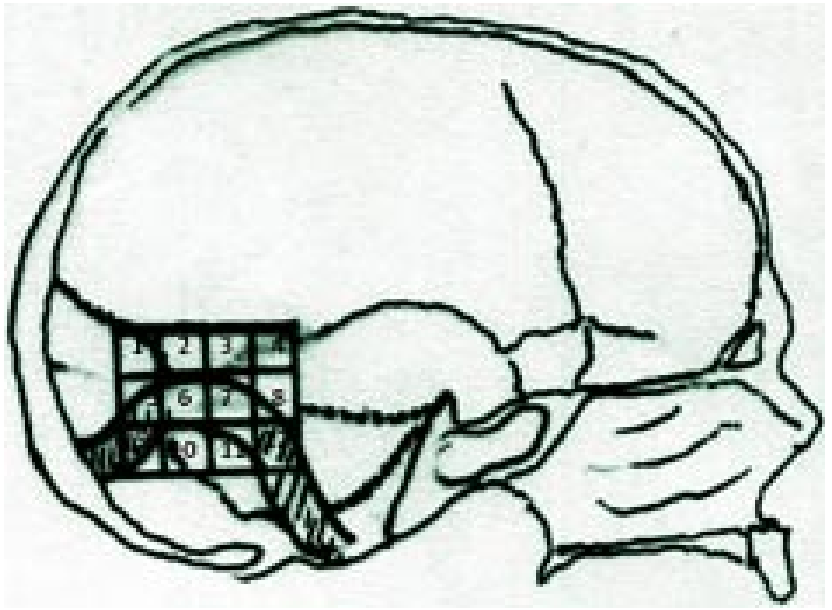

Fig. 5. The schematic appearance of inner surface of right hemicranium on sagittal section; the anatomical relationship between asterion and sigmoid-transverse sinus junction. Each grid measured $0.5 \times 0.5 \mathrm{~cm}$. On metric scale with $1.5 \times 2 \mathrm{~cm}$, the numbers represented the areas of localization of asterion.

All of the neonatal cadavers were obtained by domination. They had no cogenital anomalies of other structures and the cranial bones and vascular system of head and neck. The data analyzed using Wilcoxon test and Pairedt test.

\section{RESULTS}

The defined rough circle was posterolateral fontanelle on which asterion the center point. The diameter of rough circular posterolateral fontanelle was approximately measured as $0.50 \mathrm{~mm}$. The measurements made for the determination of location of the asterion were noted and the statistical mean, minimum and maximum values for each external and internal parameters were given in Tables II-VII.

The point asterion (posterolateral fontanelle) was found both on the left and right sides of female and male specimens. The asterion on the right side of posterior cranial fossa was located with the frequency orders as 11 . square on 12 cases (34.3\%), 7. square on 9 cases $(25.7 \%), 10$. square on 8 cases $(22.9 \%), 6$. square on 3 cases $(8.6 \%), 8$. square on 2 cases $(5.7 \%), 9$. square on one case $(2.9 \%)$ without considering sexuality. There was not any case found on 1., 2., 3., 4., and 5. squares (Table VII). According to these distribution, the supratentorial localization was not found at the right side. Frequency of the localization of asterion on left side was showed on Table I.
By the evaluation of the frequency of localization of asterion at the internal cranial base on left side without considering sexuality, the findings were arranged with the frequency as 11 . square on 11 cases $(31.4 \%), 10$. square on 10 cases $(28.5 \%), 7$. square on 6 cases $(17.1 \%), 6$. square on 5 cases $(14.3 \%), 2 ., 5$., and 12. squares in each one case (2.9\%) (Table I). The supratentorial localization was found only in one case.

The localization was also evaluated according to the sex of specimens. The localization of asterion on female newborns on left side was found as 10 . square in 7 cases (36.8\%), 7. and 11.squares in 4 cases (21.1\%), 6. square in 2 cases $(10.5 \%), 2$. and 12 . squares in one case $(5.3 \%)$. On right side, the localizations were 10 . and 11. squares in each 6 cases $(31.6 \%), 7$. square on 4 cases $(21.1 \%), 6 ., 8$. and 9. squares in one case $(5.3 \%)$ for female newborns. On left side of male newborns, the localization of asterion was found as 11 . square in 7 cases $(43.8 \%), 6$. and 10 . squares in 3 cases $(18.8 \%), 7$. square in 2 cases $(12.5 \%), 5$. square in one case $(6,3 \%)$.

On right side of male newborns, the localization distribution of asterion was found as 11. square in 6 cases (37.5\%), 7. square in 5 cases $(31.3 \%), 6$. square in 2 cases $(12.5 \%), 5$. square in one case $(6.3 \%)$.

In our study, the localization of asterion on the STJ (5., 6., 7. and 8. squares ) was found as $40 \%$ (14 case) on right side and $34 \%$ (12 case) on left side. This bony landmark, asterion was found under STJ 60\% (21 case) on right side and $63 \%$ (22 case) on left side. The localization of asterion over the STJ or by another term supratentorial localization (1., 2., 3., 4. squares) was not found on right side but it was found with the percentage of $2.9 \%$ (one case) on left side.

The distance between the asterion and the STJ on right side was measured as minimum $1.58 \mathrm{~mm}$, maximum $7.61 \mathrm{~mm}$ and with the mean value of $4.50 \mathrm{~mm}$. On right side of male newborns, these values were as minimum $1.58 \mathrm{~mm}$, maximum $7.61 \mathrm{~mm}$ and with the mean value of $4.40 \mathrm{~mm}$ and on female newborns minimum $2.57 \mathrm{~mm}$, maximum 7.52 $\mathrm{mm}$ and with the mean value of $4.57 \mathrm{~mm}$. The same distance at left side was measured as minimum $1.28 \mathrm{~mm}$, maximum $8.61 \mathrm{~mm}$ and with the mean value of $4.94 \mathrm{~mm}$. On left side of male newborns, these values were as minimum $2.84 \mathrm{~mm}$, maximum $8.01 \mathrm{~mm}$ and with the mean value of $4.90 \mathrm{~mm}$, and on female newborns minimum $1.28 \mathrm{~mm}$, maximum 7.44 $\mathrm{mm}$ and with the mean value of $4.96 \mathrm{~mm}$ (Table IV). The measurements of external and internal parameters showed no difference statistically according to left or right side of skull or sex (Tables III-V, VII). 
The correlation was made for asterion according to the localization at right or left side and for each female and male newborns with paired samples correlation test (T test) and as a result of this there was not found any important difference ( $p>0.05)$. Also the correlation was made for the distance between the asterion and the STJ at left and right sides with paired samples correlation test ( $T$ test). Totally, for each female and male newborns, we could not find any important difference ( $p>0.05)$ (Table IV).

Table I. The frequency values and percentages of localization area of the asterion 70 head-halve specimens (35 newborn craniums) based on scale diagram.

\begin{tabular}{ccccccc}
\hline Location & \multirow{2}{*}{$\begin{array}{c}\text { Total } \\
\text { Área }\end{array}$} & $\begin{array}{c}\text { Percentage } \\
(\boldsymbol{\%})\end{array}$ & \multicolumn{2}{c}{ Left side } & \multicolumn{2}{c}{ Right Side } \\
\cline { 4 - 7 } & & 1.4 & 1 & 2.9 & --- & Number \\
\hline 2 & 1 & 1.4 & 1 & 2.9 & --- & --- \\
5 & 1 & 11.4 & 5 & 14.3 & 3 & 8.6 \\
6 & 8 & 21.4 & 6 & 17.1 & 9 & 25.7 \\
7 & 15 & 2.9 & --- & --- & 2 & 5.7 \\
8 & 2 & 1.4 & --- & --- & 1 & 2.9 \\
9 & 1 & 25.8 & 10 & 28.6 & 8 & 22.9 \\
10 & 18 & 32.9 & 11 & 31.4 & 12 & 34.3 \\
11 & 23 & 1.4 & 1 & 2.9 & --- & --- \\
12 & 1 & $100 \%$ & 35 & & 35 & \\
Total & 70 & & & &
\end{tabular}

Table II. Morphometric measurements between asterion and surgical cranial landmarks in posterior cranial fossa

\begin{tabular}{lcccc}
\hline Parameter & Mean $(\mathbf{m m})$ & SD & Minimum $(\mathbf{m m})$ & Maximum $(\mathbf{m m})$ \\
\hline A-IM & 19.92 & 4.60 & 12.03 & 34.59 \\
A-PC & 31.76 & 5.66 & 22.99 & 46.81 \\
A-DS & 34.43 & 5.73 & 25.49 & 49.06 \\
A-FJ & 19.23 & 5.19 & 8.05 & 36.11 \\
A-C6 & 28.33 & 5.02 & 20.10 & 42.09 \\
A-HC & 23.06 & 5.06 & 11.87 & 33.91 \\
A-PI & 31.71 & 5.93 & 20.18 & 42.71 \\
A-FA & 29.37 & 5.38 & 20.13 & 42.47 \\
A-FL & 19.37 & 4.90 & 10.86 & 30.32 \\
A-FP & 24.95 & 4.91 & 13.38 & 33.21 \\
\hline
\end{tabular}

Asterion (A), internal acoustic meatus (IM), Posterior clinoid process (PC), Dorsum sellae (DO), Jugular foramen (FJ), Point that abducens nerve perforates the duramater (C6), Hypoglossal canal (HC), Internal occipital protuberance (PI), Middle point of anterior margin of foramen magnum (FA), Middle point of posterior margin of foramen magnum (FP), Middle point of lateral margin of foramen magnum (FL).

Table III. The left and right differences in the dimensions between asterion and anatomical landmarks in posterior cranial fossa of newborns.

\begin{tabular}{lcccc}
\hline Parameter & $\begin{array}{c}\text { Left side } \\
\text { Mean }(\mathbf{m m})\end{array}$ & SD & Rean $(\mathbf{m m})$ & SD \\
\hline A-MI & 19.69 & 4.74 & 20.16 & 4.51 \\
A-PC & 31.70 & 5.65 & 31.82 & 5.74 \\
A-DS & 34.44 & 5.73 & 34.43 & 5.81 \\
A-FJ & 19.19 & 5.18 & 19.27 & 5.28 \\
A-C6 & 28.08 & 5.09 & 28.58 & 5.00 \\
A-HC & 23.00 & 4.81 & 23.12 & 5.37 \\
A-PI & 32.02 & 5.88 & 31.41 & 6.05 \\
A-FA & 29.34 & 5.34 & 29.40 & 5.49 \\
A-FL & 19.36 & 5.02 & 19.38 & 4.84 \\
A-FP & 24.96 & 4.74 & 24.95 & 5.14 \\
\hline
\end{tabular}


Table IV. Distances between asterion and sigmoid-transvers sinus junction (STJ) according to sexes and sides in newborns.

\begin{tabular}{lcccc}
\hline Parameter & Mean $(\mathbf{m m})$ & SD & Minimum $(\mathbf{m m})$ & Maximum $(\mathbf{m m})$ \\
\hline LA-LSTJ & 4.94 & 1.64 & 1.28 & 8.61 \\
RA-RSTJ & 4.50 & 1.48 & 1.58 & 7.61 \\
LA-LSTJ (Male) & 4.90 & 1.64 & 2.84 & 7.61 \\
RA-RSTJ (Male) & 4.40 & 1.52 & 1.58 & 7.44 \\
LA-LSTJ (Female) & 4.96 & 1.69 & 1.28 & 7.52 \\
RA-RSTJ (Female) & 4.57 & 1.48 & 2.57 &
\end{tabular}

Left asterion (LA), Right asterion (RA), the junction of left sigmoid and transverse sinuses (LSTJ), the junction of right sigmoid and transverse sinuses (RSTJ).

Table V. Measurements between asterion and dural venous sinuses in posterior cranial fossa in newborns.

\begin{tabular}{|c|c|c|c|c|c|c|c|c|}
\hline \multirow{2}{*}{ Parameter } & \multirow{2}{*}{$\begin{array}{l}\text { Mean } \\
(\mathbf{m m})\end{array}$} & \multirow{2}{*}{ SD } & \multirow{2}{*}{$\begin{array}{c}\text { Min } \\
(\mathbf{m m})\end{array}$} & \multirow{2}{*}{$\begin{array}{l}\text { Max } \\
(\mathbf{m m})\end{array}$} & \multicolumn{2}{|c|}{ Left side } & \multicolumn{2}{|c|}{ Right side } \\
\hline & & & & & Mean (mm) & SD & Mean (mm) & SD \\
\hline A-TS & 17.26 & 3.36 & 9.04 & 25.10 & 17.01 & 3.17 & 17.51 & 3.18 \\
\hline A-SS & 5.89 & 2.31 & 2.43 & 13.97 & 5.97 & 2.47 & 5.81 & 2.17 \\
\hline A-SP & 17.76 & 3.54 & 11.36 & 26.05 & 17.79 & 3.85 & 17.73 & 3.25 \\
\hline A-IP & 24.73 & 4.50 & 15.19 & 33.36 & 24.89 & 4.69 & 24.57 & 4.35 \\
\hline A-SC & 30.37 & 5.71 & 19.37 & 42.53 & 30.72 & 5.49 & 30.02 & 5.99 \\
\hline A-STJ & 4.72 & 1.57 & 1.28 & 8.6 & 14.94 & 1.65 & 4.50 & 1.48 \\
\hline
\end{tabular}

Asterion (A); Transverse sinus (TS), Sigmoid sinus (SS), Confluence of sinuses (CS), Superior petrosal sinus (SP), Inferior petrosal sinus (IP), the junction of sigmoid and transverse sinuses (STJ).

Table VI. Dimensions between asterion and surgical external cranial landmarks in newborns.

\begin{tabular}{lcccc}
\hline Parameter & Mean $(\mathbf{m m})$ & SD & Minimum $(\mathbf{m m})$ & Maximum $(\mathbf{m m})$ \\
\hline A-ZR & 28.89 & 5.02 & 20.18 & 39.77 \\
A-HS & 22.30 & 4.48 & 13.50 & 30.26 \\
A-MT & 15.83 & 4.65 & 5.40 & 30.01 \\
A-PE & 35.97 & 6.81 & 23.57 & 48.97 \\
\hline
\end{tabular}

Asterion (A), Henle's spine (HS), External occipital protuberance (PO), Zygoma root ( ZR), Mastoid tip (MT).

Table VII. Right -left differences in dimensions between asterion and surgical external cranial landmarks in newborns.

\begin{tabular}{lcccccccc}
\hline \multirow{2}{*}{ Parameter } & \multicolumn{4}{c}{ Left side } & \multicolumn{3}{c}{ Right side } \\
\cline { 2 - 9 } & Mean $(\mathbf{m m})$ & SD & Min $(\mathbf{m m})$ & Max $(\mathbf{m m})$ & Mean $(\mathbf{m m})$ & SD & Min $(\mathbf{m m})$ & Max $(\mathbf{m m})$ \\
\hline A-ZR & 29.32 & 5.00 & 21.52 & 39.47 & 28.45 & 5.07 & 20.18 & 39.77 \\
A-HS & 22.46 & 4.38 & 14.08 & 30.08 & 22.15 & 4.64 & 13.50 & 30.26 \\
A-MT & 15.99 & 4.89 & 5.40 & 30.01 & 15.68 & 4.48 & 5.47 & 24.36 \\
A-PE & 35.66 & 6.25 & 24.54 & 48.25 & 36.28 & 7.41 & 23.57 & 48.97 \\
\hline
\end{tabular}

\section{DISCUSSION}

In procedures of neurosurgery one of the most important step was the decision of way of surgical approach to the lesion (Avci et al.; Day \& Tschabitscher). After this, it is necessary to know the relationship between the bony landmarks and the deep structures lying under them. The knowledge of these structural localization may be the most important point of surgeries of posterior cranial base by the existence of dural venous sinuses as a content of deep layer of cranium. The localization point of burholes for craniotomy should be suitable according to the localization of transverse and sigmoid sinuses. 
The intracranial surgical operations were started with giving suitable position to the patient and the removement of suitable bony flep. In this operation, one of the important stage was the way of intervention to the lesion (Avci et al.; Day \& Tschabitscher; Keskil et al.). After this stage, knowledge of the relationship between the surface landmarks and important deep structures lying beneath these bony landmarks gained importance. The surgical importance was increased considering important the localization of dural venous sinuses at posterior cranial fossa (Avci et al.; Bonilla et al.; Day \& Tschabitscher; Lang \& Samii).

The placement of first burrhole is one of the important approach stage of posterior cranial fossa or posterolateral cranial base surgery and it was gained importance with the unexpected injury of dural venous sinuses causing surgical complications (Avci et al.; Day \& Tschabitscher; Lang \& Samii). The surgeon prefers to place the first burrhole very close to the transverse and sigmoid sinus or below the asterion. This close placement will make the dimensions of craniotomy as minimum as possible by avoiding large scale incisions and an opportunity for early orientation (Avci et al.; Kopuz et al.; Lang \& Samii; da Silva et al.). The laboratory works and clinical experiments showed that the use of asterion as an exact respectable landmark could be the reason of different problems, but asterion still would be used as a key point for the definition of deep placement of STJ. If asterion is used as a landmark for a burrhole, it will be unavoidable of placement of the burrhole directly over or some part of dural venous sinuses. This condition will cause a risk of hemmoraghia as a result of damage of a venous sinus (Day \& Tschabitscher; da Silva et al.; Srijit et al., 2007). With these kowledges, in surgical procedures related with the posterior cranial base, the measurements which were made for defining the surface and deep bony anatomic landmarks are very important for the clinicians serves as a way of avoiding complications such as giving harm to the structures, especially venous vessels and nerves.

In adult populations of other countries minimal side dissimilarities in the location of the asterion from the root of the zygoma and the tip of mastoid process have been observed. It has been found that the male asterion was significantly higher than female one in Germans, Portuquese and Kenyans (Kemkes \& Göbel; Mwachaka et al.). Differences between male and female has also been noted in the location of other anthropologic points such as pterion and mastoid process (Aydin et al.; Kemkes \& Göbel; De Paiva \& Segre, 2003).

In previous studies it has been found that the asterion is mostly located superficial to the STJ in adults (Gharabaghi et al., 2008a; Mwachaka et al.; Srijit et al.; Ribas et al.).
Our findings are in accordance with findings in previous studies. Mwachaka et al., observed that $80 \%$ of asterion was on STJ line, $1.1 \%$ above STJ line and $18.9 \%$ below STJ line. Gharabaghi et al. (2008a) revealed that $70 \%$ of asterion was on STJ line, $7.5 \%$ above STJ line, and $22.5 \%$ below STJ by 3D volumetric image rendering. Ribas et al. showed in a study of 50 dry human skulls that the asterion position over the STJ was accurate in $78 \%$ of cases; in $17 \%$ of the cases the asterion was below the STJ. Gharabaghi et al. (2008b) demonstrated in 200 in vivo cases that asterion was projected over the STJ in $65 \%$ of cases on the right side and $75 \%$ of cases on the left side.

It had been found that asterion lied directly over the STJ in only $23.3 \%$ of cases and directly over any point of the inferior margin of the TS in $63.3 \%$ of cases (da Silva et al.). Srijit et al. utilized perspective X-ray irradiation method and noted that $91 \%$ of asterion was located on STJ line, 7\% below STJ line nd $2 \%$ above STJ line. It had been reported that the asterion was located over the STJ in 7 of the 30 cases and the asterion location varied from $13 \mathrm{~mm}$ medial to $15 \mathrm{~mm}$ inferior to the virtual position of the STJ. In none of these cases, the asterion situated laterally or superiorly to the STJ (da Silva et al.).

Sheng et al. (2012) have made known that majority of the asterion $(81 \%)$ was located on the transverse sinus side of STJ or distal-end of transverse sinus. Among to Turks on adults, the distance from the asterion to the STJ is 15.1 $\mathrm{mm}$ (10.0-22.1 mm) (Avci et al.). The same measurement in study of Day \& Tschabitscher was $19.2 \mathrm{~mm}$. We found this distance as a mean value $4.7 \mathrm{~mm}(4.9 \mathrm{~mm}$ on the left side, $4.5 \mathrm{~mm}$ on the right side on the newborns).

Day \& Tschabitscher, in their study for the definition of localization of asterion on adults, found that this point on 61 cases on right side $(61 \%)$ and 66 case on left $(66 \%)$ side was localized on the STJ (5., 6., 7., 8. squares). They reported that the asterion totally was on STJ line in $63.5 \%$ of cases, while it was located below STJ line in $28.5 \%$ and above STJ line in $8 \%$. It was found in $32(32 \%)$ cases on right side, in $25(25 \%)$ cases on left side below the STJ. The supratentorial or above the STJ localization (1., 2., 3., 4. squares) was found in $7(7 \%)$ cases on right side and in 9 $(9 \%)$ cases on left side. The same authors defined the most localization area of asterion on their scale diagram (the same scale diagram of ours) as 7 . square on right side (34\%) and 6. square on left side (46\%) (Day \& Tschabitscher). The defined exact localization of asterion on left side on 3., 11., and 12. squares as 1\%; on right side on 1., 3., 6., 8.,10.,11. and 12 . squares as $3 \%, 4 \%, 5 \%, 22 \%, 4 \%, 14 \%$ and $14 \%$, respectively; on left side 2., 3., 5., 7., 9., 10., 11. and 12. squares as $8 \%, 1 \%, 5 \%, 15 \%, 4 \%, 19 \%, 1 \%$ and $1 \%$, 
respectively, whereas a localization of asterion was not found on 2., 4., 5. and 9. squares on right side and 1., 4. and 8. squares on left side by above authors (Day \& Tschabitscher).

In our neonatal cadaver study, we found the localization of asterion as on the STJ (5., 6., 7., 8. squares) in $14(40 \%)$ cases on right side and in $12(34 \%)$ cases at left side. Additionally, it was located below the STJ (9., 10., 11., 12. squares) in $21(60 \%)$ cases on right side and in $22(63 \%)$ cases on left side. The supratentorial or above the STJ localization of asterion was not observed on right side. Furthermore, this localization was found only in one case $(2,9 \%)$ on left side. In our evaluation with the scale diagram, we determined that the most frequent localization of asterion as the 11.square both for the right and left sides $12(34 \%)$ cases for the right side and $11(31,4 \%)$ cases for the left side. We also revealed that the asterion was not located on 1., 2., 3., 4., 5. and 12. squares on right side and 1., 3., 4., 8. and 9. squares on left side. Additionally, it was found on 6 ., 7., 8., 9., 10. squares on right side as $8.6 \%, 25.7 \%, 5.7 \%$, $2.9 \%$, and $22.9 \%$, respectively and on left side on 2., 5 ., $6 ., 7 ., 10 ., 12$. squares as $2.9 \%, 2.9 \%, 14.3 \%, 17.1 \%, 28.6 \%$ and $2.9 \%$, respectively.

Our findings are in accordance with the findings of Day \& Tschabitscher according to the density of localization of asterion on the level of supratentorial and infratentorial and on the localization of the STJ but it was clear that there have been important differences at the levels of scale diagrams. This condition could be explained by the differences of specimens as newborns and it could be the effect of differences between the regions and races.

Avci et al., found the localization of asterion as an area $7 \mathrm{~mm}$ over the inferior side of transverse sinus. Kemkes \& Göbel in Germans found that asterion was 49.4 $\mathrm{mm}$ and $49.9 \mathrm{~mm}$ above the mastoid tip on the right and left sides, respectively. The same measurement was 47.50 $\mathrm{mm}$ and $47.56 \mathrm{~mm}$ for right and left sides among the Portuquese in adults. Bonilla et al., in their study, found distances of asterion, in populations of South America, as $69.6 \mathrm{~mm}$ to inion and $48.5 \mathrm{~mm}$ to external acoustic canal and $55.1 \mathrm{~mm}$ to mastoid tip. Among the Kenyans, the distances on right and left sides, respectively from the asterion to the mastoid tip was $47.8 \mathrm{~mm}$ and $47.6 \mathrm{~mm}$. The measurement between asterion and zygoma root in that study was $58.8 \mathrm{~mm}$ and $58.4 \mathrm{~mm}$ on left and right sides in adult craniums (Mwachaka et al.).

Among the adult Turks, in cadaver specimes, the distances from asterion to zygoma root, to Henle's spine and to mastoid tip were measured as $55.6 \mathrm{~mm}, 39.0 \mathrm{~mm}$ and $50.3 \mathrm{~mm}$, and in dry skulls as $56.6 \mathrm{~mm}, 43.0 \mathrm{~mm}$ and
$49.9 \mathrm{~mm}$, respectively (Avci et al.). We found the distance of asterion as $28.8 \mathrm{~mm}$ to zygoma root and $22.3 \mathrm{~mm}$ to Henle's spine and $15.8 \mathrm{~mm}$ to mastoid tip and $35.9 \mathrm{~mm}$ to external occipital protuberance in term neonatal cadavers. Additionally, we found that the asterional region has an average distance value of $19.9 \mathrm{~mm}$ to IM, $31.7 \mathrm{~mm}$ to PC, 34.4 to DO, $19.2 \mathrm{~mm}$ to $\mathrm{FJ}, 23.0 \mathrm{~mm}$ to $\mathrm{HC}$, and $31.7 \mathrm{~mm}$ to PI internally, which would be safe for reaching the posterior cranial fossa at craniotomies of newborns, decreasing the risk of complications.

Rhoton in his method in adults defined that the placement of initial burrhole far from the asterion on adults could increase the risk of complications. According to this method; there was no risk of placement of burrhole at 2 $\mathrm{cm}$ inferior to the asterion, $1 / 3$ anterior and $2 / 3$ posterior of occipitomastoid fissure. It was thought that this method was the exact way of avoiding the sigmoid sinus (Rothon; Srijit et al.). Our technique could be helpful for attempting anatomy in newborns as an alternative method to the Rhoton's. Rhoton's safe areas defined the areas of our findings as 5. square on right side and 9. square on left side. These areas could be defined as safe but it is clear that the risk of perforation of sinuses has a higher percentage on the left side. In the same way, Jannetta et al. (1986) stated that the asterion usually overlies junction of the lower half of the transverse and sigmoid sinuses .

Lang \& Samii, in their study in adults found a result as the burrhole could be placed to the region $45 \mathrm{~mm}$ posterior of suprameatal spine and $7 \mathrm{~mm}$ inferior of Frankfurt Horizontal plane because the sinuses had no opening to this region with the ratio of $92 \%$. This safety area defined by Lang \& Samii was highly similar to Rhoton's results and our defined safe areas. Some authors reported that reliability of using asterion as a surface landmark remained debatable. However its location was indespensible to identify the STJ for a successful posterior approach surgery in cranial fossa (Day \& Tschabitscher; Gharabaghi et al., 2008a; De Paiva \& Segre; Mwachaka et al.).

This localization of the asterion has not shown an important difference on right or left side or sex ( $p>0.05)$. There was no meaningful difference of distances between the asterion and STJ both according to the side or sex ( $p>0.05$ ). This distance was found as $4.5 \mathrm{~mm}$ on right side and $4.97 \mathrm{~mm}$ on left side and with general values of 4.72 $\mathrm{mm}$. By the guide of point asterion on newborns the area of $1 \mathrm{~cm} 2(0.5 \times 2 \mathrm{~mm})$ on this point which was placed on superior 4 squares of our scale diagram is suggested as a safe area of placement of first burrhole to avoid the risk of bleeding of sigmoid and transverse sinuses on craniotomies of posterior fossa. 
Our results showed that there were a great ratio of trauma of sigmoid- transverse sinus complex by the surgical approaches on point asterion. As a result, also in newborns the point asterion as an important surgical landmark for a successful surgical approach but not a safety region. We believe that the defination of landmarks such as asterion with measured distances by other important structures of internal or external cranial base may be useful for the surgeons and radiologists at the stages of diagnosis and planning for surgical approaches in this area.

DEMIR, M. T.; KOPUZ, C.; PIRZIRENLI', M. E. A.; ÇELIK, F. \& ÇORUMLU, U. Localización del asterión de acuerdo con los puntos anatómicos de la fosa craneal posterior en recién nacidos: Implicaciones clínicas. Int. J. Morphol., 33(2):685-694, 2015.

RESUMEN: El propósito de este estudio fue determinar la localización del asterion de acuerdo con los puntos anatómicos de la fosa craneal posterior y su relación con los senos de abordajes quirúrgicos posterolaterales en los recién nacidos. Fueron utilizadas 70 hemicabezas y se colocó una aguja de alrededor de $2 \mathrm{~mm}$ de diámetro en el punto central del asterion (fontanela posterolateral) en todo el tejido óseo craneal produciéndose la formación de un ángulo recto con la superficie ósea. La localización del asterion y las mediciones de los puntos de referencia anatómicos internos y externos fueron investigados en cadáveres de neonatos a término. La localización del asterion se encontró en la unión sinusal transverso sigmoide (STJ) (cuadrados 5., 6., 7., 8.) en el $40 \%$ de los casos en el lado derecho y en el 34\%, en el lado izquierdo. Además, se encontró por debajo del STJ (cuadrados 9., 10., 11., 12.) en un $60 \%$ de los casos en el lado derecho y en el $63 \%$ de los casos en el lado izquierdo. Se determinó que la localización más frecuente del asterion fue 11., tanto para los lados derecho e izquierdo, 12 casos (34\%) para el lado derecho y 11 casos $(31,4 \%)$ para el lado izquierdo. El asterion no se encuentra en los cuadrados 1., 2., 3., 4., 5. y 12. del lado derecho y 1., 3., 4., 8. y 9. del lado izquierdo. Se determinó que la región del asterion tiene una distancia promedio de $19,9 \mathrm{~mm}$ al meato acústico interno, 31,7 $\mathrm{mm}$ al proceso clinoides posterior, $34,4 \mathrm{~mm}$ al dorso selar, $19,2 \mathrm{~mm}$ al foramen yugular y 23,0 $\mathrm{mm}$ al canal hipogloso, internamente. La distancia del asterion a la raíz del hueso cigomático fue $28,8 \mathrm{~mm}$ y 22,3 $\mathrm{mm}$ a la columna vertebral, siendo de $15,8 \mathrm{~mm}$ al proceso mastoides y $35,9 \mathrm{~mm}$ a la protuberancia occipital externa. En los recién nacidos, se sugiere un área de $1 \mathrm{~cm}^{2}$ y se colocan en 4 casillas superiores de nuestro diagrama a escala, como una zona segura para la realización de la primera trepanación para evitar el riesgo de sangrado de los senos sigmoide y transverso en craneotomías de fosa posterior.

PALABRAS CLAVE: Asterion; Seno sigmoides; Seno transverso; Enfoque retrosigmoideo; Anatomía; Recién nacido; Fosa craneal posterior.

\section{REFERENCES}

Avci, E.; Kocaogullar, Y.; Fosset, D. \& Caputy, A. Lateral posterior fossa venous sinus relationships to surface landmarks. Surg. Neurol., 59(5):392-7, 2003.

Aydin, M. E.; Kopuz, C.; Demir, M. T.; Corumlu, U. \& Kaya, A. H. Localization of pterion in neonatal cadavers: a morphometric study. Surg. Radiol. Anat., 32(6):545-50, 2010.

Bonilla, G.; Algieri, R. D.; Bernadou, M. M.; Castro Barros, F.; Paday Formenti, M. E.; Dodaro, F.; Albarracin, M. \& Rodriguez, J. Asterion: anatomical landmark for posterior fossa approaches. Hosp. Aeronaut. Cent., 7(2):83-6, 2012.

Brockmeyer, D.; Gruber, D. P.; Haller, J.; Shelton, C. \& Walker, M. L. Pediatric skull base surgery. 2. Experience and outcomes in 55 patients. Pediatr. Neurosurg., 38(1):9-15, 2003.

da Silva, E. B. Jr.; Leal, A. G.; Milano, J. B.; da Silva, L. F. Jr.; Clemente, R. S. \& Ramina, R. Image-guided surgical planning using anatomical landmarks in the retrosigmoid approach. Acta Neurochir. (Wien), 152(5):905-10, 2010.

Day, J. D.; Kellogg, J. X.; Tschabitscher, M. \& Fukushima, T. Surface and superficial surgical anatomy of the posterolateral cranial base: significance for surgical planning and approach. Neurosurgery, 38(6):1079-83, 1996.

Day, J. D. \& Tschabitscher, M. Anatomic position of the asterion. Neurosurgery, 42(1):198-9, 1998.

De Paiva, L. A. \& Segre, M. Sexing the human skull through the mastoid process. Rev. Hosp. Clin. Fac. Med. Sao Paulo, 58(1):15-20, 2003.

Gharabaghi, A.; Rosahl, S. K.; Feigl, G. C.; Liebig, T.; Mirzayan, J. M.; Heckl, S.; Shahidi, R.; Tatagiba, M. \& Samii, M. Imageguided lateral suboccipital approach: part 1-individualized landmarks for surgical planning. Neurosurgery, 62 (3 Suppl. 1):18-22, 2008a.

Gharabaghi, A.; Rosahl, S.K.; Feigl, G.C.; Safavi-Abbasi, S.; Mirzayan, J.M.; Heckl, S.; Shahidi, R.; Tatagiba, M. \& Samii, M. Image-guided lateral suboccipital approach: Part 2 -impact on complication rates and operation times. Neurosurgery, 62 (3 Suppl 1):24-9, 2008 b.

Janetta, P. J.; Møller, M. B.; Møller, A. R. \& Sekhar, L. N. Neurosurgical treatment of vertigo by microvascular 
decompression of the eighth cranial nerve. Clin. Neurosurg., 33:645-65, 1986.

Kemkes, A. \& Göbel, T. Metric assessment of the "mastoid triangle" for sex determination: a validation study. J. Forensic Sci., 51(5):985-9, 2006.

Keskil, S.; Gözil, R. \& Calgüner, E. Common surgical pitfalls in the skull. Surg. Neurol., 59(3):228-31, 2003.

Kopuz, C.; Aydin, M. E.; Kale, A.; Demir, M. T.; Corumlu, U. \& Kaya, A. H. The termination of superior sagittal sinus and drainage patterns of the lateral, occipital at confluens sinuum in newborns: clinical and embryological implications. Surg. Radiol. Anat., 32(9):827-33, 2010.

Lang, J. Jr. \& Samii, A. Retrosigmoidal approach to the posterior cranial fossa. An anatomical study. Acta Neurochir. (Wien), 111(3-4):147-53, 1991.

Lang, J. Skull base and related structures: Atlas of clinical anatomy. 2nd ed. Stuttgart, Schattauer Verlag, 2001. pp.239-53.

Mwachaka, P. M.; Hassanali, J. \& Odula, P. O. Anatomic position of the asterion in Kenyans for posterolateral surgical approaches to cranial cavity. Clin. Anat., 23(1):30-3, 2010.

Ribas, G. C.; Rhoton, A. L. Jr.; Cruz, O. R. \& Peace, D. Suboccipital burr holes and craniectomies. Neurosurg. Focus, 19(2):E1, 2005.

Rothon, A. L. Surface and superficial surgical anatomy of the posterolateral craneal base: Significance for surgical planning and approach - Comment. Neurosurgery, 38(6):1083-4, 1996.

Sheng, B.; Lv, F.; Xiao, Z.; Ouyang, Y.; Lv, F.; Deng, J.; You, Y. \& Liu, N. Anatomical relationship between cranial surface landmarks and venous sinus in posterior cranial fossa using CT angiography. Surg. Radiol. Anat., 34(8):701-8, 2012.

Srijit, D.; Rajesh, S. \& Vijay, K. Topographical anatomy of asterion by an innovative technique using transillumination and skiagram. Chin. Med. J. (Engl.), 120(19):1724-6, 2007.

Sripairojkul, B. \& Adultrakoon, A. Anatomical position of the asterion and its underlying structure. J. Med. Assoc. Thai, 83(9):1112-5, 2000.

Standring, S. Gray's Anatomy: The Anatomical Basis of Clinical Practice. 40th ed. London, Churchill \& Livingstone, 2008. pp.404,412,414-417,470.

Teo, C.; Dornhoffer, J.; Hanna, E. \& Bower, C. Application of skull base techniques to pediatric neurosurgery. Childs Nerv. Syst., 15(2-3):103-9, 1999.

Tubbs, R. S.; Loukas, M.; Shoja, M. M.; Bellew, M. \& CohenGadol, A. A. Surface landmarks for the junction between the transverse and sigmoid sinuses: application of the "strategic" burr hole for suboccipital craniotomy. Neurosurgery, 65(6 Suppl.):37-41, 2009.

\section{Correspondence to: \\ Prof. Dr. Cem Kopuz \\ Körfez Mah. Atatürk Bulvarı \\ No:112, 55139 Kurupelit \\ Samsun \\ TURKEY}

Email: drkopuz@gmail.com

Received: 30-10-2014

Accepted: 10-03-2015 